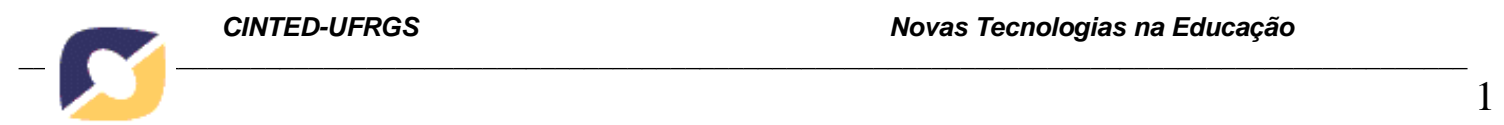

\title{
Inclusão Digital de Idosos: Um estudo sobre a Realidade do Município de Belém (Pa)
}

\author{
Francy Santos Fernandes ${ }^{1}$ - Universidade Federal do Pará \\ fernandesfrancy@hotmail.com \\ Benedito de Jesus Ferreira ${ }^{2}$ - Universidade Federal do Pará \\ ferreira@ufpa.br
}

\begin{abstract}
Resumo: Este artigo apresenta os resultados preliminares de pesquisa de campo sobre as condições com que ocorre a inclusão digital da terceira idade no município de Belém/PA. Os dados foram levantados em quatro entidades da cidade que oferecem cursos de Informática, não diferenciando os que são exclusivos para Terceira Idade e os com turmas mistas. Além disso, o artigo enumera, inicialmente, quais são as principais necessidades atendidas, as dificuldades encontradas e qual a contribuição da inclusão digital na vida dessas pessoas. Dentre as principais dificuldades no processo, podemos destacar a noção da necessidade de memorização de comandos e a dificuldade correspondente, e a questão do ritmo de aprendizagem que em certos contextos não é devidamente respeitado.
\end{abstract}

Palavras-chave: inclusão digital, inclusão social, tecnologia de informação e comunicação, terceira idade

\section{Elderly people Digital Inclusion: Diagnosis of Reality in the City of Belém (Pa)}

Abstract: This article presents the preliminary results of a field research about in which conditions occurs the digital inclusion of elderly people in the city of Belém/PA. Data were collected in four city entities that offer computer courses, available for people of all age - not differentiating the ones that are exclusive for elderly people from those for mixing groups. In addition, the article lists, initially, the primary needs, difficulties that were found and the digital inclusion's contribution in the life of these people. Among the main difficulties in the process, we highlight the notion of the need to memorize commands and the corresponding difficulty, and the question of the pace of learning that in some context is not duly observed.

Keywords: digital inclusion, social inclusion, information and communication technology, elderly people

\section{Introdução}

O envelhecimento é uma fase da vida marcada por perdas físicas e emocionais e pela tendência ao menor convívio social. O declínio das relações sociais pode levar a solidão, que para Capitanini (2000, p.69) significa "estado emocional que inclui isolamento, tristeza, apatia, insatisfação na vida, o qual é provocado pela ausência de contatos e relacionamentos importantes". A redução do contato com os entes queridos e 


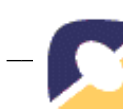

amigos pode propiciar o aparecimento de depressão.

A percepção de que o envelhecimento é uma etapa natural do desenvolvimento humano é importante para possibilitar, à nossa sociedade, maneiras de promover a participação ativa da Terceira Idade com cidadania. Lempke (2009, p. 25) afirma que "os programas educacionais para idosos também funcionam como instrumento para prolongar o processo de socialização que se inicia na infância e vai até a velhice”.

A Organização Mundial de Saúde (OMS) classifica como idosa a pessoa que atingiu a idade de 60 anos, marco caracterizado pelo início da aposentadoria e pelo declínio físico, cognitivo e sensorial.

Os dados do Censo Demográfico de 2010 demonstram o aumento da proporção da população idosa no Brasil e a diminuição da população jovem. No período compreendido entre 2000 e 2010 a população idosa aumentou $42 \%$ enquanto a população abaixo de 60 anos aumentou apenas 11\%. A tendência de crescimento projetada para os anos 2020 e 2050 demonstra a potencial inversão da chamada pirâmide etária nas próximas décadas. A figura 1 demonstra a alteração no formato da pirâmide etária dos anos de 2000 para 2010 e as projeções para 2030 e 2050 (cada faixa corresponde a 5 anos, indo de 0 a 80 anos).

Figura 1 - Pirâmide Etária do Brasil por sexo e grupo de idade

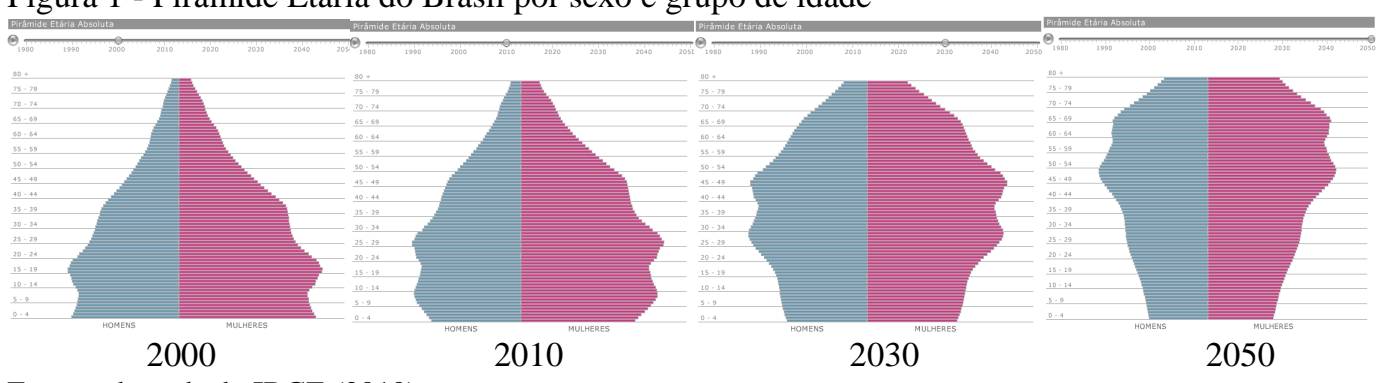

Fonte: adaptada do IBGE (2010)

Projeções do IBGE (2011) indicam que, em 2050, haverá no país 215,3 milhões de habitantes, sendo aproximadamente 65 milhões de pessoas maiores de 60 anos, ou mais precisamente, $30,21 \%$ da população. Analisando-se tais indicadores sociodemográficos, é possível o planejamento de ações de curto, médio e longo prazo, de forma a preparar o país para as necessidades futuras da população nas mais diversas áreas de atuação e produzir políticas públicas adequadas.

Mas como promover o bem estar de uma população com esse perfil projetado? Kachar (2010) enfatiza a necessidade de pesquisas sobre a mudança do perfil etário do Brasil para que a sociedade possa se preparar para o envelhecimento saudável e ativo da população. Os estudos devem focalizar várias áreas do conhecimento dentre as quais: Geriatria, Educação e Tecnologia. Nesse contexto, as Tecnologias de Informação e Comunicação (TIC) podem funcionar como instrumento para promover a inclusão social da Terceira Idade, possibilitando a socialização e perspectiva de conservação da autonomia e bem-estar dos indivíduos.

$\mathrm{Na}$ vida contemporânea as TIC se fazem cada vez mais presentes no dia-a-dia; estamos cercados de celulares, computadores, internet, caixas eletrônicos, etc., e quem não possui uma desenvoltura mínima nesse convívio terá sua autonomia reduzida. No caso dos idosos, segundo Kachar (2003) a socialização incorpora relações mediadas pelas TIC, e a geração nascida em tempos de relativa estabilidade, convive de forma conflituosa com as rápidas e complexas mudanças tecnológicas. Para Lempke (2009) é 
necessário desconstruir a imagem de decadência e exclusão geralmente associada aos idosos que querem e precisam aprender a manusear essas tecnologias para estarem incluídos digitalmente e participar efetivamente da sociedade atual. Martini (2005) ressalta que entre os objetivos da inclusão digital está a ampliação da cidadania e o combate à pobreza.

Cabe observar que a questão da inclusão digital, no caso de idosos, não se descola da questão vista de forma mais ampla. De acordo com Barbosa, Cappi e Jereissati (2011) apenas $23 \%$ dos domicílios no Norte do país possuem computador e só $14 \%$ destes dispõem de internet. Não se pode afirmar que, por se possuir computador em casa, haverá inclusão digital; é necessária, além do acesso adequado à rede mundial, a aquisição de habilidades, processo que se dá de maneira específica, no caso de indivíduos mais idosos. Apesar do norte do país ser a região que menos sofreu o efeito do envelhecimento, a tendência nacional também é acompanhada pelo estado do Pará. Pelo Censo de 2010 (IBGE, 2011), Belém (capital do estado) possuía 9,32\% de pessoas com idade superior a 60 anos. Para a OMS, uma cidade pode ser considerada envelhecida quando a proporção da população com mais de 60 anos ultrapassa $7 \%$ da população total.

Mesmo com o crescente aumento da população de idosos no município, verificase a carência de iniciativas públicas para a inclusão digital da terceira idade, assim como a pesquisas sobre o tema ainda é muito incipiente. Dessa forma, o objetivo desta pesquisa foi realizar um diagnóstico, buscando-se entender em que condições ocorre a aprendizagem para inclusão digital da terceira idade no município de Belém. Como desdobramento: quais são as principais necessidades atendidas? Quais as dificuldades encontradas? O que contribui para facilitar essa inclusão? Qual a contribuição da inclusão digital na vida dessas pessoas? A inclusão digital contribui para a inclusão social da Terceira Idade? Para isso, foi realizado um levantamento em quatro locais que oferecem cursos de formação em informática, sendo um, específico para pessoas acima de 60 anos; um segundo que se dirige a pessoas acima de 50 anos, e os outros dois para qualquer faixa etária.

Como não é possível generalizar os resultados de regiões diferentes, os dados obtidos podem confirmar ou não, estudos realizados em outras cidades. A complementaridade desses estudos justifica a presente pesquisa, como subsídio à implementação de ações de inclusão digital adequadas aos idosos.

\section{Referencial Teórico-Metodológico}

A revisão bibliográfica foi realizada tendo como base as teorias propostas localizadas em dissertações, teses, artigos e livros que nortearam a análise dos resultados, tendo em vista a dificuldade em encontrar material teórico que abordasse especificamente o tema inclusão digital da terceira idade

\subsection{Fundamentação Teórica}

Os estudos sobre o envelhecimento contribuem para o desenvolvimento de software e hardware específicos ou adaptáveis às reais necessidades dos idosos, considerando-se fatores como comunicação, relação interpessoal, limitações físicas (visuais, ergométricas, cognitivas). Também possibilitam a elaboração de metodologias 
de ensino de tecnologia da informação de forma adequada a esse segmento da população. Podem ainda oferecer subsídios para criação de políticas públicas de inserção digital dos idosos no município de Belém. Em Kachar (2003, p. 64), a ideia de investigação está presente:

É relevante investigar quais as abordagens adequadas para introduzir o idoso no universo da informática e construir estratégias metodológicas educacionais para preparar os idosos (ativos ou aposentados) no domínio operacional dos recursos computacionais. É necessário gerar a alfabetização na nova linguagem tecnológica que se instala em todos os setores da sociedade e promover a inclusão do idoso nas transformações da sociedade.

Para Kachar (2003), com o avanço da idade, as perdas cognitivas dos idosos influenciam na absorção de conhecimento; todavia, o declínio de algumas atividades não inviabiliza a apropriação e o domínio do recurso tecnológico, apenas exige um contexto educacional específico que atenda às específicas condições de aprender.

Conforme Nunes (2006), a inclusão digital diminui a dependência e aumenta a possibilidade de integração, gera novas maneiras de relações sociais, familiares e desenvolve formas de aprendizagem que atingem todas as idades, aproximando as gerações. Sales (2007, p. 34) sustenta que:

\begin{abstract}
A comunicação é fator imprescindível para manter e aumentar o círculo social e, portanto, para elevar a auto-estima. Esses fatores justificam a importância da criação de alternativas de interação para inserir o idoso em atividades como o uso do computador e suas ferramentas de comunicação e informação, que o estimulem, integrem e permitam ampliar seus objetivos de vida, além de aproximá-lo de tecnologias similares, como telefone celular e caixas eletrônicos, facilitando seu uso.
\end{abstract}

\title{
2.2 Instrumentos metodológicos
}

Esta pesquisa é de cunho quanti-qualitativo, e de natureza descritiva. Foi realizada com pessoas com idade acima de 60 anos que participam ou participaram de cursos de informática em entidades públicas e privadas do município de Belém. Os dados foram coletados por meio de um questionário com 18 perguntas abertas e fechadas, abordando tópicos relacionados a gênero, faixa etária, renda salarial, escolaridade, bem como focalizando dificuldades, barreiras, nível de utilização e a motivação para a inclusão digital. O questionário (preenchido pela autora da pesquisa) foi respondido por 101 pessoas, com idade entre 60 e 80 anos, que se encaixam no perfil de idosos urbanos. A participação na pesquisa foi espontânea, e para se manter a privacidade dos participantes, seus nomes foram alterados e referenciados por iniciais.

\section{$3 \quad$ Resultados da Pesquisa}

O município de Belém não possui política pública voltada para a inclusão digital da população idosa. Assim, foi realizada uma investigação inicial em locais no município relacionados com: assistência ao idoso, centro de convivência de idosos, abrigos, asilos, escolas particulares e em entidades de apoio a capacitação da indústria, comércio e serviço para saber se ofereciam cursos de informática ou qualquer tipo de programa de inclusão digital para idosos. 


\subsection{Locus da Pesquisa}

Foram entrevistados, no período de agosto a setembro de 2011, alunos do curso de informática de quatro entidades, que se adequaram ao perfil da pesquisa: Ver-o-Sol, Bolonha, UNITERCI e CASE. O quadro 1 apresenta um resumo das principais características dos cursos pesquisados.

Quadro 1: Caracteristicas dos cursos pesquisados.

\begin{tabular}{|c|c|c|c|c|c|c|c|}
\hline CURSO & $\begin{array}{c}\text { ALUNOS } \\
\mathbf{N}^{\circ} \text { DE } \\
\text { ENTREISTADOS }\end{array}$ & $\begin{array}{c}\text { POR } \\
\text { TURMA }\end{array}$ & $\begin{array}{c}\text { INSTRUTORES } \\
\text { EM SALA }\end{array}$ & $\begin{array}{c}\text { ALUNOS POR } \\
\text { COMPUTADOR }\end{array}$ & MATERIAL & $\begin{array}{c}\text { QUEM } \\
\text { PAGA }\end{array}$ & $\begin{array}{c}\text { ESPECÍ́ICO } \\
\text { P/ 3 }{ }^{\text {IDADE }}\end{array}$ \\
\hline Ver-o-Sol & 16 & 50 & 2 instrutores & 1 & Apostila & Grátis & não \\
\hline Bolonha & 58 & 10 & 1 instrutor & 1 & $\begin{array}{c}\text { Digitado } \\
\text { pelos alunos }\end{array}$ & Pago & $\begin{array}{c}\text { acima de } 50 \\
\text { anos }\end{array}$ \\
\hline UNITERCI & 22 & 10 & $\begin{array}{c}1 \text { instrutor e } 3 \\
\text { monitores }\end{array}$ & 1 & Apostila & Grátis & sim \\
\hline CASE & 5 & 8 & 1 instrutor & 1 & Apostila & Grátis & não
\end{tabular}

Fonte: Pesquisa de curso de informática para idosos em Belém

\subsection{Caracterização dos Participantes}

A análise preliminar do levantamento de campo indica diferenças singulares entre o público-alvo pesquisado; dentre os dados mais evidentes, revelou-se uma predominância feminina $(74 \%)$ no conjunto de alunos(as).

Em relação ao primeiro contato com o computador, observa-se que um percentual de $65 \%$ de alunos buscam a inclusão digital por meio dos cursos de informática. $\mathrm{O}$ restante dos entrevistados (7\%) tentou aprender com auxílio de familiares ou amigos; e outros, tiveram contato com o computador ainda quando estavam trabalhando (5\%).

Em relação à frequência de utilização da internet, os entrevistados que a utilizam diariamente (ou quase diariamente) chega a 66\%; $24 \%$ a utilizam uma vez por semana ou menos, geralmente, por não terem computador, ou este não ser de uso exclusivo.

A maioria dos entrevistados $(41 \%)$ tem entre 60 e 64 anos, seguidos pela faixa etária de 65 a 69 anos (28\%), e a de 70 a 74 anos com $22 \%$. Entre os entrevistados, houve apenas uma pessoa com 80 anos. Sobre o estado civil, $47 \%$ dos entrevistados é casado, $20 \%$ solteiro e $21 \%$ viúvo (registrou-se a presença de casais fazendo o curso).

Quanto à ocupação, 72\% dos entrevistados são aposentados, 18\% são donas de casa, $8 \%$ ainda trabalham e $2 \%$ são pensionistas. Dos aposentados, $15 \%$ ainda se mantêm na ativa, quer seja no mercado formal ou no informal.

A renda de $38 \%$ dos entrevistados concentra-se na faixa acima de seis salários mínimos, $20 \%$ declararam renda de até 3 salários mínimos e 17\%, até 4 salários mínimos. Apenas $7 \%$ ganham um salário mínimo e $7 \%$ estão na faixa até dois salários mínimos.

É em casa que $77 \%$ dos entrevistados usam o computador, $7 \%$ usam no trabalho, $7 \%$ usam no curso de informática, $5 \%$ usam em lan house, e $4 \%$ na casa de parentes ou amigos. Também informaram que $4 \%$ não têm computador em casa e $12 \%$ declararam que compartilham o computador com demais membros da família.

Cabe observar que as pessoas que procuram o aprendizado de informática, na maioria, possuem nível de escolaridade médio ou superior: $50 \%$ tem ensino médio completo, $30 \%$ tem curso superior completo, $3 \%$ tem o ensino médio incompleto, $5 \%$ 


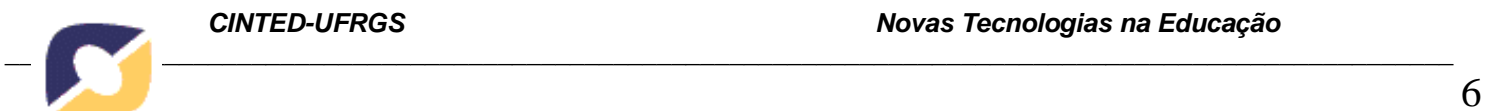

tem ensino fundamental completo e $4 \%$ tem o fundamental incompleto. $5 \%$ tem pósgraduação.

O principal objetivo apontado para inserção digital dos entrevistados é manterem-se atualizados e a comunicação com amigos e parentes de outra localidade, com um meio de comunicação mais rápido e barato. $86 \%$ usam correio eletrônico, $59 \%$ executam estudos e pesquisas, $49 \%$ usam as redes sociais e salas de bate-papo. Apenas 3\% acessa bancos e $14 \%$ fazem compras, pois não se sentem seguros para fazer essas atividades. Somente $8 \%$ admitem que jogam na internet, uma vez que a maioria considera os jogos difíceis e/ou desinteressantes.

\subsection{Motivos para Buscar a Inclusão Digital}

A maioria dos idosos relata que a maior expectativa é se comunicar de forma mais rápida e barata com familiares, principalmente filhos e amigos que moram distante.

"É muito prático se comunicar com quem está fora, enviando e-mails, cartão digital. Melhora a interação com amigos mais distantes que não vemos com freqüência." (R.F.M.R., 67 anos).

"Ficou muito mais barato e rápido falar com os meus filhos e amigos. Costumo trocar mensagens muito bonitas com meus amigos, e através do computador fico sabendo das novidades." (F.M.C., 67 anos).

"Com a internet me comunico com as minhas filhas e netos. É um meio de comunicação melhor que o telefone porque podemos ver a outra pessoa." (M.C.P.L., 68 anos).

\subsubsection{Atualização}

Os alunos da terceira idade buscam aprender o suficiente para manterem-se atualizados, independentes e ativos em uma sociedade informatizada, na qual cada vez mais estamos cercados de tecnologia. Muitos se sentem envergonhados quando lhes perguntam qual é o seu endereço eletrônico. Não ter e-mail e nem saber utilizá-lo, hoje em dia, é sinônimo de antiquado, obsoleto, ultrapassado. Os idosos se sentem mal ficando alheios ao mundo informatizado que estamos vivenciando.

"Para acompanhar o tempo, não quero ficar obsoleta, à margem da sociedade, não quero ser excluída." (D.C.M., 63 anos).

"Fiquei curiosa para ler notícias, jornais, fazer pesquisas. Futuramente quero fazer compras e ampliar os meus conhecimentos.” (M.R.O., 73 anos).

"Saber o que está acontecendo no mundo, nos portais de notícias. Eu acho fantástico, coisas que eu nunca imaginei, por exemplo, a correção automática de textos... Digito sem medo, porque se estiver errado o computador corrige na hora." (L.A.G., 69 anos).

A perspectiva de voltar ao mercado de trabalho ou melhorar sua atuação profissional também é apontada pelos idosos como motivo para querer se inserir digitalmente, $30 \%$ mencionaram que buscam na inserção digital capacitação para voltarem ao mercado, seja para complementar a renda ou para se manter ocupado. Para aqueles que ainda continuam trabalhando, não saber usar o computador e a internet é motivo de constrangimento e de rejeição no ambiente de trabalho, pois os idosos se sentem ultrapassados e desvalorizados. Também é apontada a necessidade de pesquisas e estudos, principalmente para os que voltam a estudar. Saber usar a intenet propicia aos 


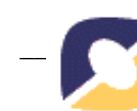

idosos a oportunidade de ter uma educação continuada.

"Necessidade de estudar para o vestibular, pois pretendo fazer o curso de Engenharia Ambiental." (R.S.V., 61 anos).

"Sou radialista da Rádio Web da UFPA, por isso quero me desenvolver e fazer eu mesma as pesquisas para os meus textos do rádio." (D.N.S., 73 anos).

"Por necessidade de pesquisar na minha área de trabalho, pois apesar de aposentado dou palestras e preciso estar atualizado.” (R.S.V., 61 anos).

\subsection{Dificuldades encontradas}

A pesquisa revela que a principal dificuldade encontrada é a "memorização dos comandos". Cabe observar que essa preocupação com a memorização já demonstra certa concepção acerca da interação com as TIC, baseada em sequência fixa de ações, ao invés de uma exploração por intuição. As falas abaixo ilustram a situação e demostram a necessidade de material diferenciado e de hardware e software adaptados a esse público.

"A maior dificuldade é o entendimento e memorização dos comandos que toda hora mudam". (R.C.C.S., 63 anos).

"Encontrar o que eu procuro na tela do computador, lembrar a seqüência para executar uma atividade.” (F.M.C., 67 anos).

Outra grande barreira é o acesso ao computador e internet. Não ter um computador em casa ou ter que usar o computador de outras pessoas da família, dificulta a inclusão digital, pois o idoso se sente constrangido em ter que disputar com os demais o acesso ao computador. Por não ter domínio da tecnologia, receiam danificar o equipamento e alterar a configuração. Desejam ter o seu próprio equipamento para ter mais tempo e liberdade para treinar, errar e também privacidade para fazer os seus próprios contatos, textos, arquivos.

"Ter um computador só meu, porque eu uso o computador do meu filho, e se eu tivesse o meи eu poderia usar a hora que eu quisesse sem precisar aguardar a disponibilidade." (M.G.R., 70 anos).

"Pretendo comprar um computador; por enquanto a minha condição financeira não permite." (A.F.A.P.C., 60 anos).

Fazer um curso de informática com pessoas mais jovens torna-se muitas vezes uma barreira para os idosos, pois eles se sentem inibidos, com medo de perguntar, existe a percepção de que os mais jovens aprendem mais rápido.

"Nos cursos anteriores que fiz $90 \%$ dos alunos era composto de jovens $e$ adolescentes, que pegavam as informações muito rapidamente e os mais idosos ficavam para trás.” (M.E.C.S., 65 anos).

“... já fiz outros cursos e não aprendi nada. Aqui tem pouca gente, os professores podem dar mais atenção, o fato de ter alunos mais jovens na sala de aula atrapalha porque eles estão mais acostumados com o linguajar, são mais rápidos, os mais velhos ficam com vergonha de perguntar quando não entendem o assunto ou se esquecem, já aqui o ritmo da aula é de acordo com a nossa capacidade de assimilação e os professores têm mais paciência." (A.F.A.P.C., 68 anos).

Os idosos desejam um conhecimento funcional voltado para suas necessidades de comunicação. Alguns alunos abandonam o curso quando sentem que já aprenderam o que queriam ou quando o curso não oferece o que eles procuram, aumentando ainda mais as barreiras enfrentadas pelos idosos. 


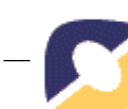

"A apostila deveria ter uma sequência lógica para executar os passos para fazer o que eu quero." (F.M.C., 67 anos).

"A apostila tem muitos detalhes, tem muitas coisinhas que eu não sei para que servem. Quero coisas práticas, não gosto de ler manual.”(L.C.B., 62 anos).

Pelos relatos dos instrutores, comumente os idosos vêm acompanhados de netos e filhos, que também se matriculam para ajudá-los.

\subsection{Ganhos Obtidos}

$\mathrm{Na}$ percepção dos participantes, a possibilidade de aprender coisas novas e ter acesso a informações de forma instantânea proporciona-lhes uma ampliação de sua visão do mundo, e da cultura contemporânea, o que aliado ao conhecimento adquirido por eles durante a vida, melhora a consciência da sua condição na sociedade e possibilita manifestações de cunho político e cidadania.

"Acompanho a evolução do mundo, fico sabendo sobre política, faço parte de um partido político e acho que vou me candidatar nas próximas eleições à vereadora e vou usar a internet para fazer propaganda e defender os direitos dos idosos." (D.C.M., 63 anos).

"As pessoas da $3^{a}$ idade têm condições de exercer atividades produtivas, basta que se tenha oportunidade de sair da inércia. Se eu me informar posso ajudar outros idosos. Eu sinto necessidade de estar atualizada na linguagem dos jovens para poder ministrar palestras no meu trabalho voluntário e a internet é uma fonte de informação.” (L.C.D., 67 anos).

"Significa mais vida e oportunidade de comunicação e interagir com as pessoas. Os idosos que ficam sozinhos começam a pensar que não têm mais capacidade, mas é o contrário, temos muito para passar aos jovens. Eu já fui convidada até para me candidatar à vereadora." (R.S.P., 75 anos).

Os idosos se sentem excluídos pela baixa familiaridade com as TIC. À medida que superam essas dificuldades, ganham confiança e sentimentos de satisfação e valorização, assim como aumenta a autoestima que os fazem querer progredir e avançar no conhecimento.

Os instrutores demonstram grande satisfação em trabalhar com a terceira idade, declarando que a experiência fez com que eles tenham mais paciência com as pessoas mais velhas. Os alunos da terceira idade também se sentem muito valorizados quando professores de outras gerações lhes dão atenção.

"O isolamento em que muitos idosos ficam é fatal para qualquer pessoa e o idoso se sente inferior diante dos outros. [A informática] Ajuda a pessoa a se soltar, se expressar, o que vai dando confiança e melhorando a autoestima." (A.S.M., 71 anos).

"Minha família se admira quando recebem e-mails meus. Eu me sinto satisfeita, gratificada, porque nessa idade conseguir aprender a usar a internet, sinto que consigo superar os desafios." (M.I.S.A., 76 anos).

"Abre um leque de conhecimento para a gente. Além do lado prazeroso, a gente se sente importante, recebendo e-mails, fazendo pesquisa, tiro boletos de pagamentos." (M.E.A.F., 61 anos).

"Me sentia descriminada no trabalho porque eu não sabia usar o computador. Fiz um curso, eu era a mais velha, só tinha gente jovem e mesmo assim me saí bem. Sinto-me muito bem porque posso chegar onde eu quiser e isso aumentou muito a minha auto-estima." (A.C.M., 61 anos). 


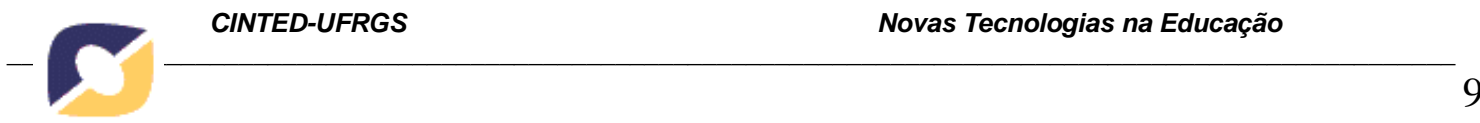

"Quando eu via um computador eu pensava que nunca ia aprender a mexer, mas percebi que quanto mais se aprende mais se quer aprender.” (M.E.S.S., 69 anos).

Em alguns casos, foram observados ganhos significativos de autonomia. Alguns alunos do curso (entidade Bolonha) se tornaram suporte para os demais, auxiliando-os fora do curso. Alguns relataram que ensinam seus amigos e empregados mais novos.

"Antes eu ficava pedindo para os outros, agora eu faço sozinha aquilo que eu quero, não dependo dos outros.” (M.G.R., 70 anos).

"No início eu não sabia nem clicar, tinha medo de escangalhar tudo, aí eu fui aprendendo, mexendo sozinha e hoje ensino a minha funcionária de 50 anos; fiz um email para ela. Tenho uma pasta no Orkut chamada "Minha Cidade" que coloco tudo sobre Belém." (L.A.G., 69 anos).

\section{Considerações Finais}

Progressivamente, mais pessoas procuram buscar as condições de um envelhecimento saudável, vencendo preconceitos e assumindo papel de cidadão autônomo. Dentre as demandas dessas pessoas observa-se que a busca de autonomia liga-se ao aprendizado em lidar com as TIC e à integração cultural pela via digital.

A presente pesquisa trás indicações de que o nível econômico influencia uma série de fatores no aprendizado e integração com as TIC, seja no aprendizado, nas dificuldades apresentadas e mesmo, nas necessidades. A aquisição de recursos físicos (computadores e conectividade) é a primeira grande barreira para a inclusão digital dos mais velhos: os indivíduos de maior poder econômico têm como demanda um professor particular, enquanto os de mais baixa renda aspiram ainda à compra de um computador, o que os possibilitaria fazer uso exclusivo.

Outra grande dificuldade é aprender a operar o equipamento. Para se trabalhar em processos educativos com a terceira idade, a didática do professor deve levar em consideração (assim como para outros segmentos) as dificuldades físicas e cognitivas específicas, o conhecimento prévio, metodologias adequadas a esse público, capacidade de interagir satisfatoriamente, equacionando o conflito de gerações que pode existir. É importante tratá-los como pessoas comuns, mas com atenção às suas especificidades.

A pesquisa indica ainda a necessidade do ambiente, sistema operacional básico e a configuração do computador estar direcionado às necessidades dos idosos. $\mathrm{O}$ curso deve estar adequado às necessidades dos idosos, evitando-se, por exemplo, excesso de detalhes técnicos. De forma geral, os participantes da pesquisa têm expectativa de um básico para se comunicar e acessar as funcionalidades da internet, como: entender genericamente o que é o computador; aprender comandos básicos de editores de textos, internet, navegadores, correio eletrônico e redes sociais; aprender a imprimir e usar os principais dispositivos externos, leitoras de CD e DVD e manipulação de arquivos e fotografias.

O ritmo de aprendizagem dos idosos deve ser respeitado, revisões constantes do conteúdo facilitam a memorização e aliviam a ansiedade provocada pelo medo do desconhecido e de errar. É importante ter-se turmas pequenas (em torno de dez alunos), e a presença de monitores para auxiliar individualmente os que apresentarem maior dificuldade, evitando-se o constrangimento perante os demais alunos.

Em sentido mais amplo, constata-se a necessidade de haver políticas públicas de inclusão digital que proporcionem a um público cada vez mais amplo, 
\begin{tabular}{lr} 
CINTED-UFRGS Novas Tecnologias na Educação & 10 \\
\hline & 10
\end{tabular}

independentemente da idade, adaptação às constantes atualizações sofrida pela tecnologia.

A inclusão digital também significa autoconhecimento e possibilidade de mudança da condição dos idosos na sociedade. Um grande desafio é tornar a vida na terceira idade plena e digna em todos os seus aspectos, e nesse sentido a inclusão digital, com aprendizado bem conduzido, é uma ferramenta bastante útil.

\section{$5 \quad$ Referências}

BARBOSA, A, CAPPI, J., JEREISSATI, T. Pesquisa sobre o uso das Tecnologias de Informação e Comunicação no Brasil. Em CETIC.br. Disponível em http://www.cetic.br/usuarios/tic/2010/apresentacao-tic-domicilios-2010.pdf em acessado em 19/01/2012.

CAPITANINI, M. E. S. Solidão na velhice: realidade ou mito? In: NERI, A. L.; FREIRE, S. A. (Org.). E por falar em boa velhice. Campinas: Papirus, 2000, p. 69-79.

IBGE, Sinopse do Censo Demográfico 2010,. Disponível em http://www.ibge.gov.br/home/estatistica/populacao/censo2010/sinopse.pdf acessado em 07/08/2011.

IBGE, Projeção da População do Brasil por Sexo e Idade - 1980-2050 - Revisão 2008 - $\quad$ v. $24 . \quad$ Disponível em http://www.ibge.gov.br/home/estatistica/populacao/projecao_da_populacao/2008/projec ao.pdf acessado em 07/08/2011.

KACHAR, V. Terceira Idade \& Informática: Aprender revelando potencialidades. São Paulo: Cortez; 2003

V. Envelhecimento e perspectivas de inclusão digital - Revista Kairós Gerontologia, São Paulo, v.13, n 2, p. 131-147, nov. 2010. acessado em 07/08/2011.

LEMPKE, N. N. S. Alfabetização digital: aprendizagem e utilização do computador na velhice, 2009, 107 f. Dissertação (Mestrado em Psicologia) - Programa de PósGraduação em Psicologia, UFJF - MG, Juiz de Fora.

MARTINI, R. Inclusão digital \& inclusão social, Revista Inclusão Social, Vol. 1, No 1, $2005 . \quad$ Disponível em http://revista.ibict.br/inclusao/index.php/inclusao/article/view/7/13 $\quad$ acessado em 07/08/2011.

NUNES, V. P. C. A Inclusão Digital e sua Contribuição no Cotidiano de Idosos: Possibilidade para uma Concepção Multidimensional de Envelhecimento, 2006. 55 f. Dissertação (Mestrado em Gerontologia Biomédica) - Programa de Pós-Graduação em Gerontologia Biomédica, PUC - RS, Porto Alegre.

SALES, M. B. de. Modelo multiplicador utilizando a aprendizagem por pares focado no idoso, 2007. 138 f. Tese (Doutorado em Engenharia e Gestão do Conhecimento) - Programa de Pós Graduação Engenharia e Gestão do Conhecimento, UFSC, Florianópolis. 